\title{
Cervical Smears: Morphological and Epidemiological Study for Intra-Epithelial Neoplasia in Lubumbashi
}

\author{
Mwenze Didier ${ }^{1}$, Mulenga Phillipe², Mukalay Abdon², Ilunga Julien ${ }^{1, ~ * ~}$ \\ ${ }^{1}$ Pathology Department, University of Lubumbashi, Lubumbashi, Democratic Republic of Congo \\ ${ }^{2}$ Public Health Department, University of Lubumbashi, Lubumbashi, Democratic Republic of Congo
}

Email address:

nijulien2011@yahoo.com (I. Julien)

${ }^{*}$ Corresponding author

\section{To cite this article:}

Mwenze Didier, Mulenga Phillipe, Mukalay Abdon, Ilunga Julien. Cervical Smears: Morphological and Epidemiological Study for IntraEpithelial Neoplasia in Lubumbashi. International Journal of Clinical Oncology and Cancer Research. Vol. 3, No. 4, 2018 , pp. 55-58. doi: $10.11648 /$ j.ijcocr.20180304.12

Received: September 1, 2018; Accepted: September 29, 2018; Published: October 25, 2018

\begin{abstract}
Cervical carcinoma is one of the most preventable cancers for conventional cervical smear may detect intraepithelial neoplasia before the invasive stage. Often cervical intra-epithelial neoplasia may be detected by conventional cervical smear. There is no cancer control policy in the Democratic Republic of Congo (DRC), as there is no cancer registry. This study was done to determine the morphological and epidemiological profile of cervical pathology in Lubumbashi. Data were selected from the Congolese League against Cancer (LCCC) registry who organized in the Democratic Republic of Congo the first cervical voluntary screening in March 2012. In total, 639 women aged from 22 to 65 years underwent cervical smears. Histopathological examination was done in case of high grade intra-epithelial neoplasia. Among all the women, 30 were living with intra-epithelial neoplasia, 24.4 and $75.6 \%$ had high grade and low grade lesions. Cytological and histological correlation was found in $65 \%$ of high grade lesion. In conclusion, this study shows a significant frequency of intra-epithelial cervical neoplasia in Lubumbashi city. Women beyond 30 years present 11 times the risk of high grade intra-epithelial lesion compared to youngers. Data are in many cases not reproducible compared with some publications. This study calls for multicentrically evaluation of intra-epithelial cervical neoplasma and for cervical cancer.
\end{abstract}

Keywords: Cervical Screening, Intra-Epithelial Neoplasia, Cancer in Developing Countries

\section{Introduction}

Cervical cancer has a devastating impact on the health of women around the world [1]. An estimated 500000 new cases of cervical carcinoma occur each year worldwide [1]. This cancer is preventable by screening cervical smear for intraepithelial neoplasia [2]. It is well known that intraepithelial neoplasia precedes invasive carcinoma after a period of about 10 years [3]. These tissue lesions are often studied by conventional cervical smears [4-8]. Other methods are used as liquid-milieu smears [5], HPV detection and visual inspection for the same purpose. The effectiveness of cervical cancer screening with exfoliative cytology was in the Scandinavian countries where the introduction of screening programs resulted in a significant decrease in the incidence of cervical cancer after 5 to 10 years [2]. The Canadian
Cancer Institute has also shown that the age-standardized mortality rate for invasive cervical cancer was divided by three between 1969 and 1990 as a result of the national screening program [10]. Developing countries have no detection policy for cervical lesions. In these countries particularly in sub-Saharan and Central Africa, South America, South-East Asia and Melanesia cervical cancer is the commonest cancer in women [1]. Cervical uterine carcinoma is the most cause of cancer death in women in these countries [1]. In India cervical cancer is second among women's cancers with an average standardized incidence of about 25/100 000 women [1]. This cancer still severely affects public health resources in sub-Saharan Africa. The age-standardized mortality rates for invasive cervical cancer in these countries are the highest as reported in Harare (Zimbabwe) and in Kampala (Uganda) [12]. Data from the Nairobi hospital registries show that cervical cancer 
accounted for $70 \%$ to $80 \%$ of all cancers of the genital tract and $8 \%$ to $20 \%$ of all cancer cases for the period from 1981 to 1990 . Every week 10 to 15 new cases of cervical cancer are recorded in Nairobi Kenya [13]. These results are similar to data from Zimbabwe where in 1995 cervical cancer accounted for $30 \%$ of all registered cancers and $80 \%$ of gynecological cancers nationally [11]. The Democratic Republic of Congo has some challenges to improve cancer survival for cervical smears are not of common use and there is neither Cancer Registry nor cancer Policy. Cervical cancer is always diagnosed later and death is the common last step in this country [14]. This study had the purpose to determine the frequency of pre-cancerous cervical lesion in Lubumbashi City. This had also the purpose to fight against uterine cervical cancer in Lubumbashi. This study was made possible following the first voluntary cervical screening organized in Lubumbashi city by the Congolese league against cancer (LCCC) in March 2012.

\section{Methods}

\subsection{Data Collection}

Data for this study were obtained from the Congolese League against Cancer registry. Women living in Lubumbashi between 25 and 65 years were selected on the basis of cervical smear for intra-epithelial neoplasia detection in March 2012.

\subsection{Criteria of Selection}

Voluntary participation was the criteria of selection. Women under 25 and over 65 as those with genital blood loss were excluded. A total of 629 women were selected.

\subsection{Cytology Treatment}

Materials were obtained and treated using conventional method: after fixing time in methanol for at least 15 minutes, slides were stained according to the Harris-Shorr technique as follows: bathing successively in ethyl alcohol $95^{\circ}, 70^{\circ}$, and $50^{\circ}$, rinsing in distilled water, staining in Harris Hematoxylin solution for 5 minutes, rinsing in distilled water, bathing in ammonia alcohol solution for 15 seconds, rinsing in water, bathing successively in alcohol $50^{\circ}, 70^{\circ}$ and $95^{\circ}$, staining in Shorr for 3 minutes, bathing alcohol $95^{\circ}$ and twice in alcohol $100^{\circ}$, bathing in two box of xylene and finally cover-slides were used before light microscopy examination.

\subsection{Material for Histology}

All women with a "high grade" lesion were treated by diathermic loop conization and the specimen was examined for histological verification. The process of tissue treatment was as followed [15]:

1. Fixation in neutral formaldehyde solution at $10 \%$ dilution for 24 hours.

2. Dehydration in 4 baths of ethanol at $60^{\circ}, 80^{\circ}, 95^{\circ}$ and $100^{\circ}$ concentration.
3. Lightening in 2 baths of xylene each lasting one hour.

4. Stay in paraffin liquid kept in oven at $60^{\circ} \mathrm{C}$ for 24 hours.

5. Inclusion of tissue using an automatic coating station.

6. Cutting of paraffin blocks with a microtome of Minot model.

7. Staining using usual method of hematoxylin-eosin.

\subsection{Material Examination}

Cyto-pathological and histopathological analyzes were made independently by 3 experimented pathologists at the Pathology Department of the University Hospital of Lubumbashi, using the modified Bethesda (3) classification. Diagnosis, if discordant between the 3 pathologists was submitted to a consensus between the 3 pathologists.

The cytological aspects included all the lesions according to the modified Bethesda classification. The histological aspects concerned only the verification of high-grade lesions in cytology and were interpreted according to the morphological classification of intraepithelial neoplasia proposed by WHO in 2003 [17].

Six classes were retained: (1) inadequate smear, (2) smear within normal limits, (3) cytology compatible with inflammatory changes (4) and epithelial neoplasia. This category had 2 sub-classes: low grade and high grade intraepithelial neoplasia.

Slides were considered inadequate or unreadable for cell scarcity or thick spreading smears. Cases were considered normal when intraepithelial lesions or malignant suspected cells and inflammatory changes were not observed. Inflammation was defined in any case with absence of neoplastic changes and presence of reactive features.

\subsection{Parameters Studied}

Parameters of this study included epidemiological (age of women) and morphological data. Morphological data included:

Quality of smears

Presence or absence of cellular alterations

\subsection{Statistical Analysis}

Data were collected on a Compaq CQ58 laptop. Epi Info 2011 software was used to analyze cytological data. Frequencies expressed as percentage were calculated. Chisquare and Odds ratio tests were used for comparison of correlation between intra- epithelial lesion and the age of women. The difference was significant for the value of $p$ $<0.05$.

\section{Results}

\subsection{Age of Women}

The mean age of women was $39 \pm 8.4$ years $(n=629$, ranges: 22 and 65 years). 


\subsection{Cytological Classification}

Samples were unsatisfactory in $4 \%$ of cases, neoplastic in $13 \%$, without cytological abnormalities in $9.4 \%$ and inflammatory lesions in $73.5 \%$. Table 1 reports these findings.
Neoplastic smears were sub-classified in high grade $(24.4 \%$, $\mathrm{n}=20)$ and low grade $(75.6 \%, \mathrm{n}=62)$. Table 2 is reporting these data.

Table 1. Cytological evaluation of smears $(n=629)$.

\begin{tabular}{llllll}
\hline Evaluation & Inadequate Smears & CIN & Normal Smears & Inflammatory Smears & Total \\
\hline Number & 25 & 82 & 59 & 463 & 629 \\
$\%$ & 4 & 13 & 9.4 & 73.6 & 100 \\
\hline
\end{tabular}

CIN (Cervical intra-epithelial neoplasia).

Table 2. Classification of Cervical Intra-epithelial neoplasia $(n=82)$.

\begin{tabular}{llll}
\hline Grade & Low Grade CIN & High Grade CIN & Total \\
\hline Number & 62 & 20 & 82 \\
$\%$ & 75.6 & 24.4 & 100 \\
\hline
\end{tabular}

\subsection{Risk Factor}

The risk for women to live with high grade intra-epithelial neoplasia was 11.9 times in women older than 36 years than Youngers women. This difference was statistically significant $\left(\mathrm{OR}=11.9\right.$; IC95\%=3.1-45.4; $\left.\chi^{2}=14.9 ; \mathrm{p}<0.001\right)$. This is reported in table 3.

Table 3. Correlation between CIN grade and age $(n=82)$.

\begin{tabular}{llll}
\hline Age & High grade CIN & Low grade CIN & Total \\
\hline$\geq 36$ years & 17 & 20 & 37 \\
$\leq 35$ years & 3 & 42 & 45 \\
Total & 20 & 62 & 82 \\
\hline
\end{tabular}

$\mathrm{OR}=11.9 ; \mathrm{IC} 95 \%=3.1-45.4 ;$ corrected $\chi^{2}=14.9 ; \mathrm{p}<0.001$.

\subsection{Comparison Cytology by Histopathology for High Grade Intra-Epithelial Neoplasia}

Histological correlation was found in 13 cases of the 20 high grade lesions or $65 \%$.

\section{Discussion}

There are several methods to highlight pre-cancerous cervical lesions. Conventional cervico-vaginal smear is a method that was used by other authors $[3,4,6,8,11,12]$. However, some authors prefer to screen for these lesions by other methods. This is particularly the case of Danchez who proposes the demonstration of the P16 INKa protein by immunocytochemistry. However, this method would be indicated for high grade cervical intraepithelial neoplasia [13]. Hul et al also propose using the HPV test as a primary approach for screening for cervical cancer [9], as many studies have confirmed that HPV testing.

\subsection{Age of Women}

The mean age of women in the present study is $39 \pm 8.4$ years and the range is 22 to 65 years. This compared to data found by Koutsky seems different. In fact, the mean age in the last study was $26 \pm 7$ years with age ranges from 16 to 50 years. The difference between the selected age's range may explain this difference.

\subsection{Quality of Smears}

Smears are unsatisfactory in $4 \%$ of cases in the present study. Mpiga et al. and Dagneaux reported in their studies 1.3 and $3.5 \%$ of inadequate smears. It is not possible to confirm a difference or a correlation between these observations.

\subsection{Smears without Bnormalities}

There are $9.4 \%$ cervical smears without any abnormality in this study. In the study reported by Mpiga et al. [2], there were $59.9 \%$ of smears without any abnormality. The border between normal smears and some inflammation may be the reason of this difference. This bias may be reduced in multifocal studies by accredited workers.

\subsection{Smears with Inflammatory Changes}

This present study reports $73.6 \%$ of inflammatory changes in women cervical smears. If compared to data from Mpiga et al. [2], who reported only $35.3 \%$ cases of inflammation, there is a great difference. This may be explained by many factors as human and experience of examiners. It may be useful to conduct multifocal study by accredited workers.

\subsection{Intra-Epithelial Neoplasia}

Among all the women, 13\% have intra-epithelial cervical neoplasia in this study. Data published by Tebeu et al. and Koutsky et al. reported 7.9 and $25 \%$ of intra-epithelial neoplasia of the cervix. These observations are another call for standardized analysis in multi--centrically study.

\subsection{Risk Factor of Intra-Epthelial Cervical Neoplasia}

This study have enlightened that women ranging from 36 years and more have 11.9 time the risk to develop high grade intra-epithelial cervical neoplasia. Ronco et al. [15], in their study found that grade 2 intra -epithelial cervical neoplasia had 2 time the risk to be found in women of more than 35 years compared to those youngest. At least one first Papsmears should be than recommended for cancer prevention in sexually active women before 35 years.

\subsection{Concordance Between Cytology and Histology}

It is well-known that cytology can sometime lead to false positive diagnosis. Histological confirmation remains useful. 
In this study, high grade intra-epithelial cervical neoplasia were submitted to tissue examination. In $65 \%$ of the cases, the diagnosis was confirmed. In Leroy et al. and Koutsky et al. researches, 77 and $68 \%$ of cytological diagnosis were confirmed by histology. This is an argument to recommend every time a biopsy after pap-smear if possible before any active decision for intra-epithelial cervical neoplasia.

\section{Conclusion and Recommendations}

This study was done to determine the morphological and epidemiological profile of cervical pathology in Lubumbashi. Data were selected from the Congolese League against Cancer (LCCC) register who organized cervical voluntary screening in March 2012.

Six hundred thirty nine (639) women underwent cervical smears (Pap-smear) and histopathological examination was done in case of high grade intra-epithelial neoplasia. Thirty women were living with intra-epithelial neoplasia. Among them, 20 and 65 women to mean 24 and $75.6 \%$ had high and low grade lesions. Cytological and histological correlation was found in $65 \%$ of high grade lesion.

This study shows a significant frequency of intra-epithelial cervical neoplasia in Lubumbashi city. Women beyond 30 years present 11 times the risk of high grade intra-epithelial lesion compared to Youngers. Data are in many cases not reproducible compared with some publications. Multicentrically evaluation of intra-epithelial cervical neoplasma and pre-cervical cancer screening program are challenges for improving women's survival.

\section{References}

[1] Parkin DM, Whelan SL, Ferlay J, Raymond L, Young J. Cancer jncidence in five Continents. Vol VII (IARC Scientific Publication N 143). International Agency for Research on Cancer: Lyon, France, 1997.

[2] Mpiga É, Ivanga M, Koumakpayi IH, Engohan-Aloghe C, Ankély JC, Belembaogo E, et al. Intérêt de l'inspection visuelle à l'acide acétique et au soluté de Lugol avec colposcope dans le dépistage des lésions du col utérin au Gabon. Pan Afr Med J. 2015; 22(1).

[3] Bergeron C, Cartier I, Guldner L, Lassalle M, Savignoni A, Asselain B. Lésions précancéreuses et cancers du col de l'utérus diagnostiqués par le frottis cervical, Ile-de-France, enquête Crisap, 2002. Bull Epidemiol Hebd. 2005; 2:5-6.
[4] Dagneaux I. Cytologie cervicale: Comment améliorer la détection de cellules anormales et la qualité des frottis? Apport des techniques en milieu liquide et couche mince implications en médecine générale. Louvain Med. 2003; 122:193-202.

[5] Dagneaux I. Cytologie cervicale en milieu liquide: intérêt en médecine générale. " La revue de la médecine générale" 2001. 2001; 185:304-79.

[6] Schwartz D. Dépistage cytologique du cancer du col de l'utérus par prélèvement en milieu liquide [PhD Thesis]. University of Geneva; 2002.

[7] Bergeron C. Frottis conventionnel ou milieu liquide? in Bernard Blanc. Le dépistage du cancer du col de l'utérus. $2005 ; 103-115$.

[8] Zeggai M, Sebiane S. Gestion des FCV (Frottis Cervicaux Vaginaux) de CHU Tlemcen [PhD Thesis]. 2014.

[9] Huh WK, Ault KA, Chelmow D, Davey DD, Goulart RA, Garcia FA, et al. Use of primary high-risk human papillomavirus testing for cervical cancer screening: interim clinical guidance. Gynecol Oncol. 2015; 136(2):178-182.

[10] Banza K, Kizonde J, Unga M, Muiach K, Kabila B, Kalenga MK. Cancer du col de l'utérus: problématique de la prise en charge. À Propos De. 1999; 40.

[11] Leroy J, Gondry J. Le programme de dépistage français: historique et modalités. Dépist Cancer Col L'utérus. 2005; 69-80.

[12] Tebeu PM, Sandjong I, Nkele N, Fokoua S, Achu P, Kouam L, et al. Lesions pre cancereuses du col uterin en zone rurale: Etude transversale. Med D'Afrique Noire. 2005;2005(52):1.

[13] Dachez R. Intérêt des nouveaux marqueurs dans la prise en charge des lésions précancéreuses du col utérin. J Gynécologie Obstétrique Biol Reprod. 2008;37(1):S152-S154.

[14] Koutsky LA, Holmes KK, Critchlow CW, Stevens CE, Paavonen J, Beckmann AM, et al. A cohort study of the risk of cervical intraepithelial neoplasia grade 2 or 3 in relation to papillomavirus infection. N Engl J Med. 1992;327(18):12721278.

[15] Ronco G, Giorgi-Rossi P, Carozzi F, Confortini M, Dalla Palma P, Del Mistro A, et al. Efficacy of human papillomavirus testing for the detection of invasive cervical cancers and cervical intraepithelial neoplasia: a randomised controlled trial. Lancet Oncol. 2010;11(3):249-257. 